\title{
Guidelines for screening and surveillance of asymptomatic colorectal cancer in patients with inflammatory bowel disease
}

\author{
J A Eaden, J F Mayberry
}

Gut 2002;51 (Suppl V):v10-v12

$\mathrm{P}$ atients with ulcerative colitis (UC) are at increased risk of colorectal carcinoma. ${ }^{12}$ Many clinicians practice colonoscopic surveillance in these patients in the hope of detecting dysplasia or an early cancer at a surgically curable stage. However, a recent audit of gastroenterologists showed such surveillance to be disorganised and inconsistent. ${ }^{3}$ Much debate surrounds the efficacy and cost effectiveness of surveillance programmes in $\mathrm{UC}^{4-6}$ because they were introduced without benefit of randomised controlled trials.

The following guidelines should bring uniformity to the process and be of help to both surgeons and physicians. The colorectal cancer risk in patients with colonic Crohn's disease is similar to that in $\mathrm{UC}^{78}$ and thus the guidelines for UC should be equally applicable to such patients with Crohn's disease.

\section{EXECUTIVE SUMMARY}

I Surveillance colonoscopies should be performed when the disease is in remission. (Recommendation Grade: $\mathbf{C}$ ).

2 All patients should have a screening colonoscopy after 8-10 years that will also clarify disease extent. (Recommendation Grade: C).

3 Regular surveillance should begin after 8-10 years (from onset of symptoms) for pancolitis and after 15-20 years for left sided disease. (Recommendation Grade: C).

4 As the risk of cancer increases exponentially with time, there should be a decrease in the screening interval with increasing disease duration. For patients with pancolitis, in the second decade of disease a colonoscopy should be conducted every three years, every two years in the third decade, and yearly by the fourth decade of disease. (Recommendation Grade: C).

5 Two to four random biopsy specimens every $10 \mathrm{~cm}$ from the entire colon should be taken with additional samples of suspicious areas. (Recommendation Grade: C).

6 Patients with primary sclerosing cholangitis (including those with an orthotopic liver transplant) represent a subgroup at higher risk of cancer and they should have annual colonoscopy. (Recommendation Grade: C).

\section{EPIDEMIOLOGY OF COLORECTAL CANCER RISK}

Although it is clear long term UC carries a colorectal cancer risk, its magnitude has been difficult to estimate. Cancer is rarely encountered when disease duration is less than $8-10$ years, but thereafter the risk rises at approximately $0.5 \%$ to $1.0 \%$ per year. ${ }^{9}$ Most cancers arise in pancolitis and there is general agreement that there is little or no increased risk associated with proctitis while left sided colitis carries an intermediate cancer risk. ${ }^{10}{ }^{11}$ Patients with onset of colitis early in life are thought to have an increased risk compared with older patients. ${ }^{1011}$ A comprehensive meta-analysis of all published studies reporting a colonic cancer risk in UC has recently been presented ${ }^{12}$ and shows the risk for any patient with colitis to be $2 \%$ at 10 years, $8 \%$ at 20 years, and $18 \%$ after 30 years of disease.

\section{INTERVENTION}

Surveillance is best performed during remission to eliminate the difficulty of differentiating reactive change from dysplasia on histological biopsy. ${ }^{13}$ All patients with UC should be advised to have a screening colonoscopy 8-10 years after onset of symptoms (not date of diagnosis) to check disease extent. Periodic colonoscopy should begin 8 to 10 years after disease onset for extensive colitis and 15 to 20 years for left sided disease. ${ }^{14}$ As the risk of cancer increases exponentially with time, a schedule with a gradual decrease in the screening interval should be adopted. ${ }^{15}$ In the second decade a colonoscopy should be conducted every three years, every two years in the third decade of disease, and yearly by the fourth decade. ${ }^{15}$

Surveillance should start in childhood if necessary. For example, a child who presents with total colitis aged 5 should start to undergo cancer surveillance aged 15. There is no evidence in the literature recommending an upper age limit at which surveillance should be terminated. Each case has to be considered on its own merits and comorbidity taken into account. It may be reasonable to discontinue regular colonoscopy once a patient reaches 70 years or when comorbidity makes colonoscopy (or possible subsequent colectomy) distressing, of unacceptably high risk, or impossible. However, this decision should be taken after consultation with the patient.

It may be argued that colonoscopy is not necessary in a patient with left sided disease. However, disease can extend and if these patients only have a flexible sigmoidoscopy any extension of disease may be missed. Therefore, although there is no evidence, it is recommended that such patients should have a colonoscopy every five years with a flexible sigmoidoscopy in the interim years.

During colonoscopy a full examination should be performed with careful inspection of the entire mucosa and random biopsy specimens should be taken at regular intervals. The more samples taken, the better will be the sensitivity for detecting dysplasia. However, the more samples taken, the higher will be the pathology costs, the longer will be the time (and the associated costs) of the procedure, and the greater will be the morbidity of the colonoscopy. While it has not been studied, it seems a reasonable trade off between sensitivity and cost/morbidity to sample the colon with two to four biopsy specimens taken from each $10 \mathrm{~cm}$ of the colon. ${ }^{16}$ Some studies report that more than $50 \%$ of neoplasia associated with UC develops in the distal colon. ${ }^{17-19}$ These authors advocate additional sampling of the rectosigmoid area with the goal of

Abbreviations: UC, ulcerative colitis; DALM, dysplasia associated lesions or masses; HGD, high grade dysplasia; LGD, low grade dysplasia 
improving the diagnostic yield from random biopsy specimens. ${ }^{17}$ Particular attention should be paid to raised lesions (dysplasia associated lesions or masses (DALMs)) as such areas may harbour dysplasia or carcinoma. ${ }^{2021}$ Extra specimens should also be taken from irregular plaques, unusual ulcers, or strictures. ${ }^{20-22}$

\section{Primary sclerosing cholangitis}

Several studies have indicated those patients with concomitant primary sclerosing cholangitis (PSC) are at a higher risk of colorectal neoplasia. ${ }^{23-25}$ The absolute cumulative risk of cancer or dysplasia in this subset of patients has been estimated to be $9 \%$ after 10 years, $31 \%$ after 20 years, and $50 \%$ after 25 years of colitis. ${ }^{26}$ Patients with PSC often have quiescent colitis and so it is difficult estimating the exact onset of UC in this group. For the above reasons it is recommended such patients should have annual surveillance colonoscopy.

\section{Primary sclerosing cholangitis after orthotopic liver transplantation}

An increased risk of colorectal cancer after orthotopic liver transplantation in patients with PSC and UC has also been reported with an incidence of approximately $1 \%$ per person per year. ${ }^{27}$ The risk is therefore clinically important and thus annual surveillance colonoscopy is recommended in the posttransplant period.

\section{Dysplasia as a predictor of cancer}

Dysplasia is generally recognised to be premalignant but the likelihood of progression to cancer is difficult to predict. In a literature review Bernstein et al analysed 1225 patients who had undergone colonoscopic surveillance. ${ }^{28}$ If a DALM was found at colonoscopy, immediate colectomy revealed cancer in $43 \%$ of patients regardless of the grade of dysplasia in the DALM. When high grade dysplasia (HGD) in flat mucosa was the initial discovery, immediate surgery revealed carcinoma in $42 \%$ to $67 \%$ of the colectomy specimens. ${ }^{28}{ }^{29}$ Thus, whenever a DALM or HGD is identified and confirmed by two expert gastrointestinal pathologists, this is a strong indication for colectomy. ${ }^{20}$ However, recent studies have highlighted the possibility of performing a colonoscopic polypectomy with subsequent increased surveillance (every six months) for patients who develop a pedunculated adenoma-like DALM (either within or outside areas of colitis) and in whom no other areas of flat dysplasia are recognised..$^{30}{ }^{31}$ This alternative management plan may be offered to patients but it should be remembered that the polyp (DALM) may still be the first warning sign of cancer and colectomy should be considered.

In Bernstein's paper $29 \%$ of patients with low grade dysplasia (LGD) showed progression at some time to HGD, DALM, or cancer. ${ }^{28}$ Moreover, the St Mark's Hospital surveillance study indicates the five year predictive value for HGD or cancer in patients with LGD is a troubling $54 \%{ }^{29}$ Therefore the presence of LGD, even in flat mucosa, should be considered just as much an indication for colectomy as finding HGD or a DALM without waiting for a confirmatory colonoscopy. ${ }^{131619}$ A second experienced pathologist should confirm any ambiguity in the histological results. If a patient is reluctant to undergo colectomy, they should be aware of their increased risk for carcinoma and will at least require increased surveillance. Colonoscopy should be conducted every six months until two consecutive colonoscopies are negative for any level of dysplasia thereafter.

\section{COST AND BENEFITS}

UC has has an incidence varying from 6-15 per 100000 population/year ${ }^{32}{ }^{33}$ and the prevalence is approximately 12 times this figure. Thus in a community of 300000 one would expect 30 new cases per year and a prevalence of 360 patients. A previous study conducted in Leicestershire ${ }^{34}$ estimated that
$40 \%$ of patients with UC will have total/subtotal colitis and $20 \%$ will have left sided disease. This correlates with 144 patients having pancolitis and 72 having left sided disease in a population of 300000 . In the study by Probert et al $61 \%$ of the population had disease for more than eight years and $14 \%$ had disease for more than 15 years. ${ }^{34}$ This would mean that there would be approximately 88 patients with pancolitis of greater than eight years duration and 10 patients with left sided disease of more than 15 years duration-that is, the period when regular surveillance in these two groups should begin. The cost of a colonoscopy is estimated as $£ 150$ (as per other BSG guidelines). If an average of one colonoscopy every two years is assumed for each group, a gastroenterologist would perform 44 colonoscopies for pancolitis and five for left sided disease. The cost of surveillance would therefore be $(44 \times £ 150)+$ $(5 \times £ 150)=£ 7350$ per year. The cost of surveillance in Crohn's colitis based on data from another study from Leicester ${ }^{35}$ (calculated in the same way as above) would be $£ 2250$ per year.

The Leeds group have assessed the cost effectiveness of surveillance in UC by auditing 12 published surveillance programmes. ${ }^{36}$ Using stringent criteria they concluded only $12 \%$ of enrolled patients could be counted as surveillance successes. Other studies are more positive concerning the benefits of surveillance with respect to mortality. Data from the 18 year surveillance programme in the USA by Choi et al demonstrated that cancer was detected at an early stage in $80 \%$ of surveyed patients, compared with only $41 \%$ non-surveyed UC patients. ${ }^{37}$ The overall five year survival rate was $77 \%$ for the surveillance group compared with only $36 \%$ for the control group $(\mathrm{p}<0.03)$. A case-control study by Karlen et al has also found that surveillance may reduce colorectal cancer mortality. ${ }^{38}$

The hazard rate of surveillance colonoscopy with multiple biopsies seems to be low. ${ }^{39}$ In the analysis by Koobatian and Choi, the overall complication rate associated with surveillance colonoscopy was $0.26 \%$. British experience has been similar with no incidence of complication recorded during 811 surveillance colonoscopies. ${ }^{40}$ Thus the hazard rate seems comparable to diagnostic colonoscopy. ${ }^{39}$

Patients should be encouraged to take their aminosalycylate medication as the recent literature suggests that regular consumption of 5-ASA compounds may reduce their colorectal cancer risk. ${ }^{41-43}$

Patients need to be aware that surveillance cannot guarantee a reduced cancer risk but rather offers a reasonable chance of detecting precancer or symptomless cancer. ${ }^{44}$ This should be made clear to patients along with an estimate of their individual risk so that those who are unenthusiastic about surveillance can make an informed decision.

\section{RECOMMENDATIONS FOR AUDIT}

The attendance of patients at colonoscopy will need to be audited in approximately five years time. This will permit time for implementation of surveillance programmes across the country and will give some indication of whether patients are complying with the surveillance regimen. Ideally computerised systems should be used that automatically send defaulters a further appointment. We know defaulters are more likely to develop colorectal cancer and for their cancers to be identified at a later stage. ${ }^{45}$ The follow up of such patients is critical to the success of any surveillance programme.

\section{Authors' affiliations}

J A Eaden, J F Mayberry, Leicester General Hospital, Gwendolen Road, Leicester, UK

Correspondence to: Dr J F Mayberry; imaybe@globalnet.co.uk

\section{REFERENCES}

1 Devroede GJ, Taylor WF, Sauer WG, et al. Cancer risk and life expectancy of children with ulcerative colitis. N Engl J Med 1971;285:17-21. Category:III 
2 Edwards FC. Truelove SC. The course and prognosis of ulcerative colitis. Part IV: Carcinoma of the colon. Gut 1964;5:15-22. Category:III

3 Eaden JA, Ward B, Mayberry JF. How British gastroenterologists screen for colonic cancer in ulcerative colitis: an analysis of performance. Gastrointest Endosc 2000;52:153-8. Category:IV

4 Axon AT, Lynch DA. Surveillance for ulcerative colitis does not and cannot work. Gastroenterology 1994;106:1 129-31. Category:IV 5 Gyde S. Screening for colorectal cancer in ulcerative colitis: dubious benefits and high costs. Gut 1990;31:1089-92. Category:IV

6 Provenzale D, Kowdley KV, Arora S, et al. Prophylactic colectomy or surveillance for chronic ulcerative colitis? A decision analysis. Gastroenterology 1995; 109: 1 188-96. Category:Ilb

7 Ekbom A, Helmick C, Zack M, et al. Increased risk of large-bowel cancer in Crohn's disease with colonic involvement. Lancet 1990;336:357-9. Category:III

8 Sachar DB. Cancer in Crohn's disease: dispelling the myths. Gut 1994;35:1507-8. Category:IV

9 Ransohoff DF. Colon cancer in ulcerative colitis. Gastroenterology 1988;94:1089-91. Category:IV

10 Gyde SN, Prior P, Allan RN, et al. Colorectal cancer in ulcerative colitis: a cohort study of primary referrals from three centres. Gut 1988;29:206-17. Category:III

11 Ekbom A, Helmick C, Zack M, et al. Ulcerative colitis and colorectal cancer. A population-based study. N Engl J Med 1990;323:1228-33. Category:III

12 Eaden JA, Abrams K, Mayberry JF. The risk of colorectal cancer in ulcerative colitis: a meta-analysis. Gut 2001;48:526-35. Category:Ilb

13 Riddell RH, Goldman H, Ransohoff DF, et al. Dysplasia in inflammatory bowel disease: standardised classification with provisional clinical applications. Hum Pathol 1983;14:931-66. Category:IV

14 Riddell RH. Screening strategies in gastrointestinal cancer. Scand J Gastroenterol Suppl 1990;175:177-84. Category:IV

15 Lashner BA, Hanauer SB, Silverstein MD. Optimal timing of colonoscopy to screen for cancer in ulcerative colitis. Ann Intern Med 1988;108:274-8. Category:IV

16 Lashner BA, Watson AJM. McDonald J, et al, eds. Evidence based gastroenterology and hepatology. London: BM Books, 2000:221-9. Category:IV

17 Choi PM. Predominance of rectosigmoid neoplasia in ulcerative colitis and its implication on cancer surveillance. Gastroenterology 1993;104:666-7. Category:III

18 Connell WR, Talbot IC, Harpaz N, et al. Clinicopathological characteristics of colorectal carcinoma complicating ulcerative colitis. Gut 1994;35:1419-23. Category:III

19 Woolrich AJ, DaSilva MD, Korelitz BI. Surveillance in the routine management of ulcerative colitis: the predictive value of low grade dysplasia. Gastroenterology 1992;103:431-8. Category:III

20 Blackstone MO, Riddell RH, Rogers G, et al. Dysplasia-associated lesion or mass (DALM) detected by colonoscopy in long-standing ulcerative colitis: an indication for colectomy. Gastroenterology 1981;80:366-74. Category:III

21 Brostrom O, Lofberg R, Ost A, et al. Cancer surveillance of patients with long-standing ulcerative colitis: a clinical, endoscopical and histological study. Gut 1986;27:1408-13. Category:III

22 Reiser JR, Waye JD, Janowitz HD, et al. Adenocarcinoma in strictures of ulcerative colitis without antecedent dysplasia by colonoscopy. Am J Gastroenterol 1994;89:119-22. Category:III

23 Brentnall TA, Haggitt RC, Rabinovitch PS, et al. Risk and natural history of colonic neoplasia in patients with primary sclerosing cholangitis and ulcerative colitis. Gastroenterology 1996;1 10:331-8. Category:III

24 Broome U, Lindberg G, Lofberg R. Primary sclerosing cholangitis in ulcerative colitis. A risk factor for the development of dysplasia and DNA aneuploidy. Gastroenterology 1992;102:1877-80. Category:III
25 Kornfeld D, Ekbom A, Ihre T. Is there an excess risk for colorectal cancer in patients with ulcerative colitis and concomitant primary sclerosing cholangitis? A population based study. Gut 1997;41:522-5 Category:III

26 Broome U, Lofberg R, Veress B, et al. Primary sclerosing cholangitis and ulcerative colitis. Evidence for increased neoplastic potential. Hepatology 1995;22:1404-8. Category:III

27 Loftus EV Jr, Aguilar HI, Sandborn WJ, et al. Risk of colorectal neoplasia in patients with primary sclerosing cholangitis and ulcerative colitis following orthotopic liver transplantation. Hepatology 1998;27:685-90. Category:III

28 Bernstein CN, Shanahan F, Weinstein WM. Are we telling patients the truth about surveillance colonoscopy in ulcerative colitis? Lancet 1994;343:71-4. Category:IV

29 Connell WR, Lennard-Jones JE, Williams CB, et al. Factors affecting the outcome of endoscopic surveillance for cancer in ulcerative colitis. Gastroenterology 1994;107:934-44. Category:III

30 Rubin PH, Friedman S, Harpaz N, et al. Colonoscopic polypectomy in chronic colitis: conservative management after endoscopic resction of dysplastic polyps. Gastroenterology 1999;117:1295-300. Category:III

31 Engelsgierd $M$, Farraye FA, Odze RD. Polypectomy may be adequate treatment for adenoma-like dysplastic lesions in chronic ulcerative colitis. Gastroenterology 1999;117: 1288-94. Category:III

32 Devlin HB, Datta D, Dellipiani AW. The incidence and prevalence of inflammatory bowel disease in North Tees Health District. World J Surg 1980;4:189-93. Category:III

33 Stowe SP, Redmond SR, Stormont JM. An epidemiologic study of inflammatory bowel disease in Rochester New York: hospital incidence. Gastroenterology 1990;98:104-10. Category:III

34 Probert CSJ, Jayanthi V, Pinder D, et al. An epidemiological study of ulcerative proctocolitis in Indian migrants and the indigenous population of Leicestershire, 1972-89. Gut 1992;33:687-93. Category:III

35 Jayanthi V, Probert CSJ, Pinder D, et al. Epidemioloy of Crohn's disease in Indian migrants and the indigenous population in Leicestershire. Q J Med 1992;82:125-39. Category:III

36 Lynch DAF, Lobo AJ, Sobala GM, et al. Failure of colonoscopic surveillance in ulcerative colitis. Gut 1993:34:1075-80. Category:III

37 Choi PM, Nugent FW, Schoetz DJ, et al. Colonoscopic surveillance reduces mortality from colorectal cancer in ulcerative colitis. Gastroenterology 1993;105:418-24. Category:III

38 Karlen P, Kornfeld D, Brostrom O, et al. Is colonoscopic surveillance reducing colorectal cancer mortality in ulcerative colitis? A population based case control study. Gut 1998;42:711-14. Category:III

39 Koobatian GJ, Choi PM. Safety of surveillance colonoscopy in long-standing ulcerative colitis. Am J Gastroenterol 1994;89:1472-5. Category:III

40 Lennard-Jones JE, Melville DM, Morson BC, et al. Precancer and cancer in extensive ulcerative colitis: findings among 401 patients over 22 years. Gut 1990;31:800-6. Category:III

41 Eaden JA, Abrams K, Ekbom A, et al. Colorectal cancer prevention in ulcerative colitis: a case-control study. Aliment Pharmacol Ther 2000; 14:145-53. Category: III

42 Pinczowski D, Ekbom A, Baron J, et al. Risk factors for colorectal cance in patients with ulcerative colitis: a case-control study. Gastroenterology 1994:107: 1 17-20. Category: III

43 Moody GA, Jayanthi V, Probert CSJ, et al. Long term therapy with sulphasalazine protects against colorectal cancer in ulcerative colitis: a retrospective study of colorectal cancer risk and compliance with treatment in Leicestershire. Eur J Gastroenterol Hepatol 1996;8:1 179-83. Category: III

44 Lennard-Jones JE. Young GP, Rozen P, et al, eds. Prevention and early detection of colorectal cancer. London: W B Saunders, 1996:217-38. Category:IV

45 Jones HW, Grogono J, Hoare AM. Surveillance in ulcerative colitis: burdens and benefit. Gut 1988;29:325-31. Category:III 